\title{
IL6/sIL6R regulates TNFa-inflammatory response in synovial fibroblasts through modulation of transcriptional and post- transcriptional mechanisms
}

\author{
Alvaro Valin ${ }^{1,2^{*}+}$, Manuel J. Del Rey ${ }^{1 \dagger}$, Cristina Municio ${ }^{1}$, Alicia Usategui ${ }^{1}$, Marina Romero ${ }^{1}$, Jesús Fernández-Felipe ${ }^{1}$,
} Juan D. Cañete ${ }^{3}$, Francisco J. Blanco ${ }^{4}$, Yolanda Ruano ${ }^{5}$, Gabriel Criado ${ }^{1}$ and José L. Pablos ${ }^{1,6^{*}}$

\begin{abstract}
Introduction: The clinical efficacy of specific interleukin- 6 inhibitors has confirmed the central role of IL6 in rheumatoid arthritis (RA). However the local role of IL6, in particular in synovial fibroblasts (SF) as a direct cellular target to IL6/sIL6R signal is not well characterized. The purpose of the study was to characterize the crosstalk between TNFa and IL6/SIL6R signaling to the effector pro-inflammatory response of SF.
\end{abstract}

Methods: SF lines were stimulated with either TNFa, IL6/SIL6R, or both together, for the time and dose indicated for each experiment, and where indicated, cells were treated with inhibitors actinomycin $D$, adalimumab, ruxolitinib and cycloheximide. mRNA expression of cytokines, chemokines and matrix metalloproteases (MMPs) were analyzed by quantitative RT-PCR. Level of IL8/CXCL8 and CCL8 in culture supernatants was measured by ELISA. Mononuclear and polymorphonuclear cells migration assays were assessed by transwell using conditioned medium from SF cultures. Statistical analyses were performed as indicated in the corresponding figure legends and a $p$-value $<0.05$ was considered statistically significant.

Results: The stimulation of SF with IL6/sLL6R and TNFa, cooperatively promotes the expression of mono- and lymphocytic chemokines such as IL6, CCL8 and CCL2, as well as matrix degrading enzymes such as MMP1, while inhibiting the induction of central neutrophil chemokines such as IL8/CXCL8. These changes in the pattern of chemokines expression resulted in reduced polymorphonuclear (PMN) and increased mononuclear cells (MNC) chemoattraction by SF. Mechanistic analyses of the temporal expression of genes demonstrated that the cooperative regulation mediated by these two factors is mostly induced through de novo transcriptional mechanisms activated by IL6/sLL6R. Furthermore, we also demonstrate that TNFa and IL6/sIL6R cooperation is partially mediated by the expression of secondary factors signaling through JAK/STAT pathways.

Conclusions: These results point out to a highly orchestrated response to IL6 in TNFa-induced SF and provide additional insights into the role of IL6/sIL6R in the context of RA, highlighting the contribution of IL6/SIL6R to the interplay of SF with other inflammatory cells.

Keywords: IL6, TNFa, Soluble receptor, Synovial fibroblast, Inflammatory response, Rheumatoid arthritis, Cross-talk, Transcriptional mechanisms, Post-transcriptional mechanisms, JAK/STAT

\footnotetext{
*Correspondence: valin_af@yahoo.com; jlpablos@h12o.es

${ }^{\dagger}$ Alvaro Valin and Manuel J. Del Rey contributed equally to this work.

'Grupo de Enfermedades Inflamatorias y Autoinmunes, Instituto de

Investigación Hospital 12 de Octubre (i+12), Madrid, Spain

Full list of author information is available at the end of the article
}

(c) The Author(s). 2020 Open Access This article is licensed under a Creative Commons Attribution 4.0 International License, which permits use, sharing, adaptation, distribution and reproduction in any medium or format, as long as you give appropriate credit to the original author(s) and the source, provide a link to the Creative Commons licence, and indicate if changes were made. The images or other third party material in this article are included in the article's Creative Commons licence, unless indicated otherwise in a credit line to the material. If material is not included in the article's Creative Commons licence and your intended use is not permitted by statutory regulation or exceeds the permitted use, you will need to obtain permission directly from the copyright holder. To view a copy of this licence, visit http://creativecommons.org/licenses/by/4.0/ The Creative Commons Public Domain Dedication waiver (http://creativecommons.org/publicdomain/zero/1.0/) applies to the data made available in this article, unless otherwise stated in a credit line to the data. 


\section{Background}

Interleukin-6 (IL6) is a pleiotropic cytokine with either proor anti-inflammatory effects depending on the cellular context and the pathophysiological state. IL6 plays a central role in local and systemic manifestations of RA and represents a successful therapeutic target $[1,2]$. Stromal and immune cells produce IL6 upon induction with major inflammatory activators such as tumour necrosis factor $\alpha$ (TNF $\alpha)$ or Interleukin 1-beta (IL1 $\beta$ ). Normal physiological concentrations of IL6 in human serum are relatively low, but rapidly increase under pathological conditions $[3,4]$. Synovial fibroblasts (SF) of the lining are the primary source of IL6 mRNA and protein in the synovium of RA patients [5].

Central to the IL6 context dependent function is the receptor system gp130/IL6R. In contrast to the ubiquitously expressed subunit gp130, the membrane subunit IL6R is mostly restricted to hepatocytes, myeloid cells and some lymphocytes. In contrast resident cells, including fibroblasts, can only respond to IL6 through transsignaling mediated by soluble IL6 receptor (sIL6R) $[6,7]$. While both pro- and anti-inflammatory effects have been associated to signal activation of the fully-competent receptor gp130/IL6R, signaling mediated through gp130/ sIL6R has been mostly linked to the induction of proinflammatory programs [8]. Interestingly, in the context of inflammatory arthritis, increased synovial sIL6R levels correlate with enhanced joint destruction and leukocyte recruitment $[3,7,9]$, but the role of the IL6/sIL6R transsignaling on inflamed synovial tissue is poorly known.

SF are essential players in RA pathophysiology, undergoing significant hyperplasia in rheumatoid arthritis (RA) and responding to exogenous proinflammatory stimuli, particularly to TNF $\alpha$, by producing a large variety of proinflammatory, bone destructive and cartilagedestructive mediators [10] thus contributing to perpetuate the inflammatory milieu in the joint. Interestingly, a recent investigation has demonstrated the cooperative role of TNF $\alpha$ and IL6/sIL6R in regulating the cell cycle and viability of synovial fibroblasts cells, accelerating RASF proliferation [11], suggesting that the crosstalk between these two factors may enhance the pathological impact of SF cells in RA.

The hierarchy of TNF $\alpha$ in SF inflammatory activity has been intensively studied in the last decades $[12,13]$. SF have a central role in the recruitment and retention of leukocytes in the inflamed joint [14-16] as well as in many other effector mechanisms resulting in chronic inflammation and joint destruction [10].

The clinical efficacy of both TNF $\alpha$ and IL6 antagonists has been extensively demonstrated in RA patients [17]. However, although many efforts have focused in understanding the specific pathogenic role of IL6 in adaptive immunity in arthritis, much less is known about the direct effects of IL6 trans-signaling on the synovial inflammatory process.
In this study, we show that IL6 trans-signaling induces an inflammatory response in SF that modulates the robust $\mathrm{TNF} \alpha$-induced inflammatory signal, by regulating the cytokine and chemokine expression pattern. Furthermore, although IL6/sIL6R has a limited impact on the expression of matrix degrading enzymes, it regulates the expression profile of specific matrix metalloproteases induced by TNF $\alpha$. Our results point out to a highly orchestrated response to these key cytokines on the SF effect or response in RA.

\section{Methods}

\section{Patients and cells}

SF cultures were established by explant growth of synovial tissues obtained by arthroscopic knee biopsies from patients without previous joint disease at elective arthroscopy for minor traumatic lesions, or patients with RA at the time of prosthetic replacement surgery. Patients signed a written informed consent, and the study was approved by the Ethics Committee of Hospital 12 de Octubre, Madrid, Spain ( $\mathrm{N}^{\circ}$ CEI:17/085). All methods involving humans were performed in accordance with the relevant guidelines and regulations. SF were cultured in Dulbecco's modified Eagle's medium (DMEM) supplemented with 10\% heat inactivated fetal bovine serum (FBS) (Lonza, Verviers, Belgium) and used after 3rd passage. For all tests SF lines were stimulated with either TNF $\alpha$, IL6/sIL6R, or both together in DMEM $0.5 \% \mathrm{FBS}$, the time and dose of the treatment will be indicated for each experiment. TNF $\alpha$, IL6 and sIL6R (PreproTech, Rocky Hill, NJ, USA) were reconstituted according to manufacturer instructions. Where indicated, cells were treated with inhibitors Actinomycin D $(10 \mu \mathrm{g} / \mathrm{ml})$ (SigmaAldrich Quimica SA, Madrid, Spain), Adalimumab $(10 \mu \mathrm{M})$ (AbbVie, North Chicago, IL, USA), Ruxolitinib (1 $\mu \mathrm{M})$ (Selleckchem, Houston, TX, USA) and Cycloheximide $(5 \mu \mathrm{M})$ (Sigma-Aldrich Quimica SA).

\section{mRNA analysis}

First-strand cDNA synthesis was performed using $2 \mu \mathrm{g}$ of total RNA with High-Capacity cDNA Reverse Transcription kit (Applied Biosystems, Foster City, CA, USA) according to manufacturer protocol. Samples were analyzed by quantitative RT-PCR (RT-qPCR) with gene-specific primer pairs (Additional file 1: Table S1) on an Applied Biosystem 7500 Fast Real-Time PCR System (Applied Biosystem) using Power Sybr Green PCR Master Mix (Applied Biosystems). Values were normalized to those of the endogenous reference (HPRT1 gene) using the $2^{-\Delta \Delta C t}$ method. In each case, multiple reactions were performed using 4-6 independent biological replicates.

\section{Enzyme-linked immunosorbent assay (ELISA)}

Concentrations of IL8/CXCL8 and CCL8 in culture supernatants were determined by ELISA (Biolegend Inc., 
San Diego, CA, USA) according to the manufacturer protocols. The read-out for all ELISAs was carried out with a MultiskanEX plate reader (ThermoScientific).

\section{Cell migration assay}

Mononuclear and polymorphonuclear leukocytes were obtained from peripheral blood from healthy donors $(n=$ 7) by density gradient centrifugation using Lympholytepoly (Cederlane Laboratories, Burlington, Canada). Cell migration was assessed using $6.5 \mathrm{~mm}$ Transwell with $5.0 \mu \mathrm{m}$ pore polycarbonate membrane insert (Corning Inc., Corning, NY, USA). $0.3 \times 10^{6}$ cells in DMEM $0.5 \%$ FBS were seeded in the upper chamber of the transwell. In the lower chamber we added conditioned medium from SF cultures $(n=4)$ stimulated for $48 \mathrm{~h}$ with either TNF $\alpha$ $(10 \mathrm{ng} / \mathrm{ml})$ or IL6 and sIL6R (50 $\mathrm{ng} / \mathrm{ml}$ each). After an incubation for $4 \mathrm{~h}$, migrated cells from the lower chamber were collected and analyzed by flow cytometry with a BD FACSCalibur instrument (Becton Dickinson, San José, CA, USA). Subpopulations of polymorphonuclear (PMN) and mononuclear cells (MNC) were identified by forward and side scatter. By combining donors and SF cultures, a total of 19 experiments were performed.

\section{Statistical analysis}

Data were analyzed using GraphPad Prism software v6.0 (GraphPad Software, San Diego, CA, USA). Statistical analyses were performed as indicated in the corresponding figure legends. A $p$-value $<0.05$ was considered statistically significant $\left(" p<0.05,{ }^{* * *} p<0.01,{ }^{* * * *} p<0.001,{ }^{* * * * * * *} p<0.0001\right)$.

\section{Results}

\section{Comparative analysis of genes regulated by TNFa or IL6/ sIL6R signaling in SF}

To investigate the relative contribution of IL6 to the SF inflammatory response, we analyzed the expression pattern of a large group of cytokines, chemokines and matrix metalloproteases (MMPs) with important roles in RA pathophysiology. We first confirmed the lack of effect of IL6 alone compared to IL6/sIL6R or TNF $\alpha$ on the expression of known target genes such as CCL2 and IL6 (data not shown) in cultured SF. Furthermore, despite individual baseline differences on gene expression, both RA and non-RA cultured SF respond similarly to TNF $\alpha$ and/or IL6/sIL6R stimulation (data not shown) and therefore, SF from both healthy and RA donors were indistinctly used.

In dose-response experiments, RT-qPCR analyses showed that TNF $\alpha$ induced the expression of the cytokine IL6, chemokines genes IL8/CXCL8, CCL2, CCL5 and CCL8, and MMPs genes $M M P 1, M M P 3$ and MMP10 (Fig. 1a). IL6/ sIL6R induced the expression of IL6 itself, mononuclearcells recruiting chemokines such as CCL2 or CCL8 but no the neutrophil-recruiting chemokine gene IL8/CXCL8 and in contrast to the robust activation of MMPs mediated by
TNFo, only $M M P 1$ was partially expressed upon stimulation by IL6/sIL6R trans-signaling at the higher dose tested (Fig. 1b). The magnitude of gene inductions by IL6/sIL6R was 2100 times lower than by TNFa.

Overall, IL6 trans-signaling mediates effects partially overlapping to those of TNFo in SF, supporting the coordinated expression of cytokines, chemokines and matrix metalloproteases central to RA pathophysiology.

\section{IL6/sIL6R trans-signal modulates the TNFa-induced inflammatory response of SF}

To investigate IL6 trans-signaling regulation of the inflammatory response in SF, we stimulated SF cultures with different suboptimal doses of TNF $\alpha$ plus a fixed dose of IL6 and sIL6R $(50 \mathrm{ng} / \mathrm{ml})$ according to dose-response assays of representative genes regulated by each factor (Fig. 1). Cooperative stimulation of SF with both TNF $\alpha$ and IL6/sIL6R enhanced the expression of a common regulated gene such as IL6 (Fig. 2a). Although the observed increased expression of CCL8 and MMP1 was not statistically significant $(p=$ 0.25 and $p=0.43$ respectively, at the higher dose of TNF $\alpha$ ), further mRNA and protein expression analysis along the present study demonstrated the consistency of the increase shown for those genes. In contrast, $M M P 3$, a gene specifically activated by TNF $\alpha$ but not IL6/sIL6R, was not affected by IL6 trans-signaling (Fig. 2a). IL6 has been shown to regulate the expression pattern of chemokines on stromal cells to drive the transition from the recruitment of neutrophils to mononuclear cells [12]. Consistently, TNF $\alpha$ induced mRNA and protein expression of the neutrophilrecruiting chemokine IL8/CXCL8 was partially inhibited by the trans-signal activation of IL6/sIL6R in SF, whereas TNFo and IL6/sIL6R cooperated to up-regulate the protein expression of mononuclear leukocytes chemoattractant chemokine CCL8 (Fig. 2a and b). Interestingly, IL6/sIL6R also inhibited the TNF $\alpha$-induced expression of MMP10, an enzyme linked to the resolution of inflammation by macrophages [18] (Fig. 2a).

To analyze the functional implications of the switch in the pattern of chemokines after the cooperative stimulation with TNF $\alpha$ and IL6/sIL6R, we performed a cell migration experiment using conditioned media from SF cultures as chemoattractant for leukocytes. Conditioned media from SF cultures treated with both TNF $\alpha$ and IL6/sIL6R reduced significantly the percentage of polymorphonuclear (PMN) cells in comparison with medium from TNF $\alpha$-stimulated cultures (Fig. 2c). Likewise, TNF $\alpha$ plus IL6/sIL6R conditioned media induced a significant increase in the recruitment of mononuclear cells (MNC) (Fig. 2c).

\section{IL6/sIL6R regulates the kinetics of the TNFa-inflammatory response}

Expression of genes activated by continuous exposure to TNF $\alpha$ is determined by transcriptional and post- 

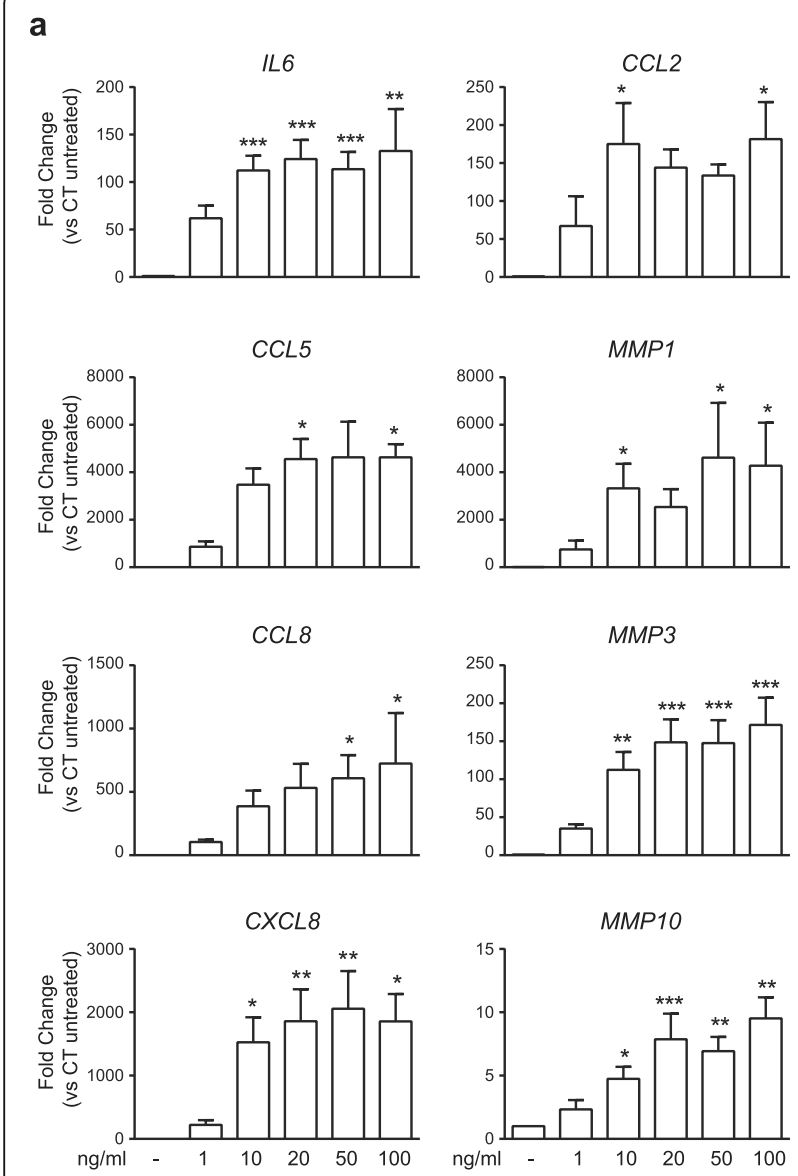

Fig. 1 Dose-response expression of genes in SF. SF were stimulated for $24 \mathrm{~h}$ with increasing doses of either TNFa (a) or IL6/sIL6R (b). Graphics show the changes in mRNA expression of indicated genes in relation to untreated control. Mean \pm SEM from three to six SF lines (*Kruskal-Wallis with Dunn's multiple comparisons test) transcriptional mechanisms that regulate its level and kinetics [19-21]. To distinguish the potential regulation of these mechanisms upon induction with IL6/ sIL6R, we first set the temporal pattern of induction for analyzed genes.

The kinetics of genes stimulated by TNF $\alpha$ in SF mostly fit into the three broad classes, as previously described in other cell types [19] (Additional file 2: Figure S1a). Thus, the expression of an early gene (IL6) was consistently detected at $0.5 \mathrm{~h}$ upon induction, while intermediate genes (CCL2, IL8/CXCL8) are observed before $2 \mathrm{~h}$ and late expression genes (CCL8, MMP1) later than $2 \mathrm{~h}$. The expression of genes mediated by continuous exposure of IL6/ sIL6R fit into a similar pattern of induction, although some of the genes that are common to both factors fall into a different category. The induction of IL6 and MMP1 follows identical kinetics for both inflammatory factors. In contrast, the expression of CCL8 or CCL2 induced by IL6/ sIL6R showed faster kinetics than that mediated by TNFo, showing CCL2 a less stable induction (Additional file 2: Figure S1b). These results more likely reflect differences b
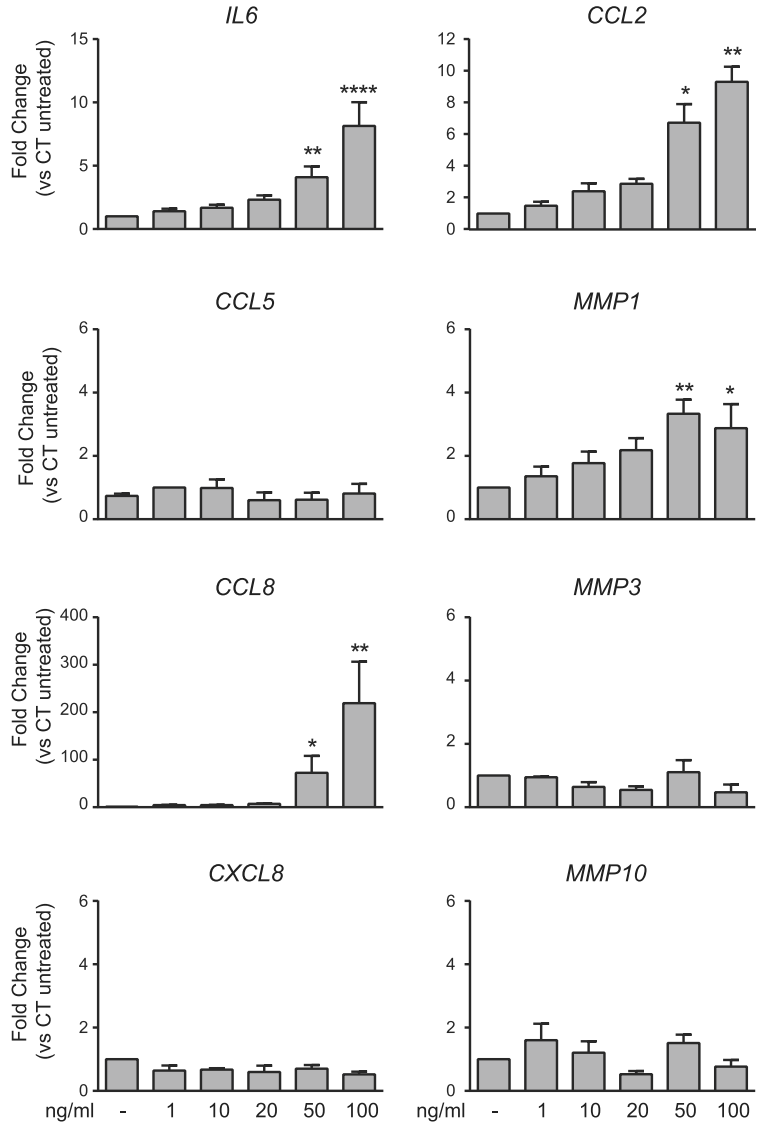

in the underlying regulatory mechanisms induced by either inflammatory cytokine.

The expression kinetics of genes co-stimulated with TNF $\alpha$ and IL6/sIL6R may provide information about the molecular mechanisms operating in the cooperative induction of genes. For all TNF $\alpha$-induced genes, kinetics was maintained after co-stimulation with IL6/sIL6R, but differences were observed in the time of the cooperative effect (Fig. 3). The increase of $I L 6$ and the decrease of $I L 8 / C X C L 8$ expression by IL6/sIL6R was detectable as soon as $30 \mathrm{~min}$ upon induction, more likely showing changes in transcription and/or mRNA stability mechanisms. However, increased expression of intermediate and late expression genes such as CCL2, CCL8 or MMP1 occurs at later time, suggesting that secondary factors may underlie the cooperative expression of these genes (Fig. 3a). A similar pattern of expression was obtained when we analyzed the protein released to the culture medium (Fig. 3b). Although not statistically significant, a moderate IL8/CXCL8 inhibition was detectable at $6 \mathrm{~h}$ after induction, while enhanced expression of CCL8 was only detectable later at $24 \mathrm{~h}$ (Fig. 3b). 


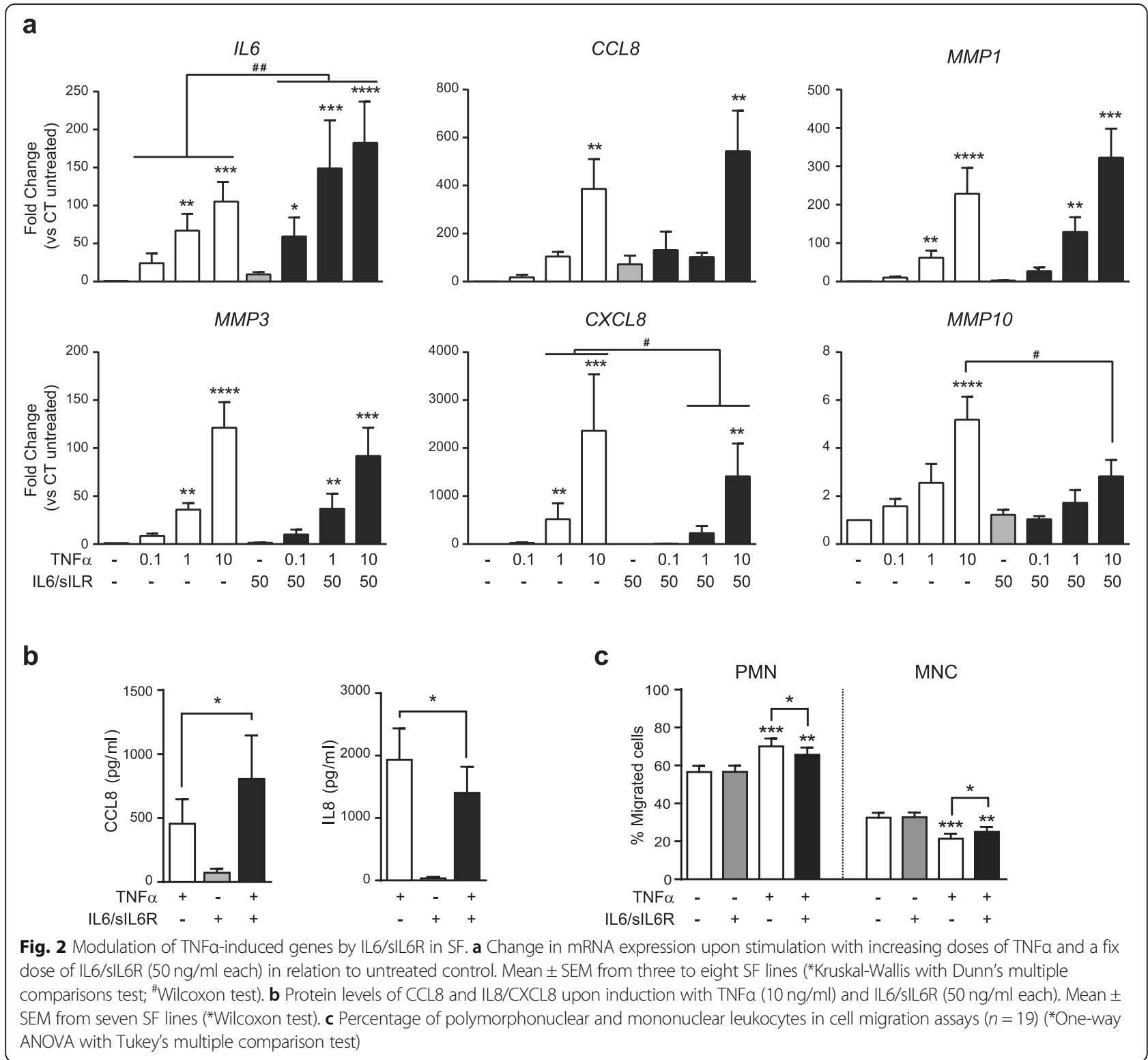

IL6/sIL6R modulates the inflammatory expression profile through de novo transcriptional mechanisms

Accumulation of mRNA may be influenced by ongoing transcription or mRNA stability. To investigate the relative contribution of mRNA stability to the induction of genes mediated by TNF $\alpha$ or IL6/sIL6R in SF, we measured changes in mRNA expression over time after blocking transcription with actinomycin D (ActD). We determined mRNA expression after $24 \mathrm{~h}$ of induction with either TNF $\alpha$ or IL6/sIL6R, relative to the baseline value before the addition of ActD. Our results showed that all tested genes stimulated by IL6/sIL6R responded similarly, with half-lives of mRNA transcripts decay varying from 0.8 to $2 \mathrm{~h}$ (Fig. 4a). In contrast, mRNAs induced by TNF $\alpha$ were on average more stable, lasting more than $2 \mathrm{~h}$ for most genes. The half-life of decay for IL6 mRNA stimulated by TNF $\alpha$ was shorter than for the rest of the genes, but similar to that stimulated by IL6/sIL6R ( 0.8 to $2 \mathrm{~h}$ ) (Fig. $4 \mathrm{~b}$ ). We could not determine the half-life of decay for MMP3, since we found no consistent decrease in stability up to 4 $\mathrm{h}$ after treatment with ActD. These results suggest that, while both transcriptional and post-transcriptional mechanisms are involved in the modulation of TNF $\alpha$ induced genes, the short half-life of IL6/sIL6R induced mRNAs may reflect a dominant role for de novo transcription. We also observed that co-stimulation of SF with both TNF $\alpha$ and IL6/sIL6R did not significantly modify the half-life of analyzed genes (Fig. 4c), suggesting that regulation of the mRNA stability of TNF $\alpha$-induced genes is not affected by the modulation after trans-signal activation of IL6/sIL6R. 


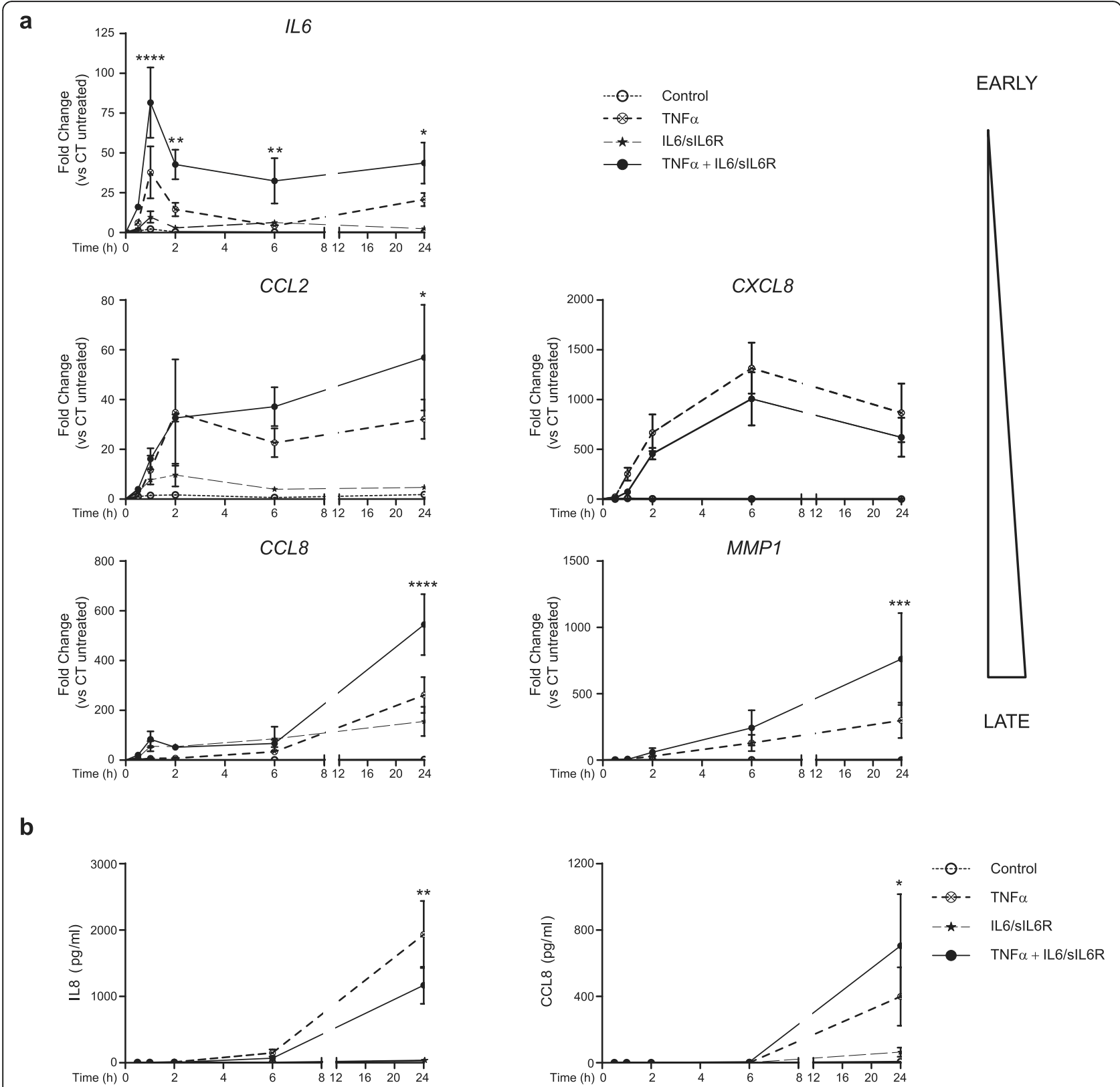

Fig. 3 Kinetic patterns of cooperative gene expression in SF. SF were cultured in the presence or absence of TNFa (10 ng/ml), IL6/sll $6 \mathrm{R}(50 \mathrm{ng} / \mathrm{ml}$ each) or both. a Representative genes $1 L 6, C C L 2, I L 8 / C X C L 8, C C L 8$, and MMP1 mRNA expression of four to six independent cultures. $\mathbf{b} \| \mathrm{L} 8 / C X C L 8$ and CCL8 protein in supernatants of six independent SF cultures. Values are mean \pm SEM (vs control, *2way ANOVA with Fisher's LSD multiple comparisons test)

Recent reports have also demonstrated that a prolonged TNFo exposure for longer than $24 \mathrm{~h}$ promotes the stability of mRNA expression in fibroblasts by epigenetic mechanisms, influencing the temporal order of induction of inflammatory genes $[19,21,22]$. To distinguish the potential role of these priming mechanisms, we first examined gene expression changes in response to TNF $\alpha$ withdrawal. We cultured SF in the presence of TNF $\alpha$ for $24 \mathrm{~h}$, removed the inflammatory input by washing the cells, and added new medium with adalimumab (ADA) to block residual
TNFo and with IL6/sIL6R for additional $24 \mathrm{~h}$ (Fig. 5). SF pre-exposed to TNF $\alpha$ and treated with ADA did not display enhanced induction of early (IL6, CCL2 and IL8/ CXCL8) nor late genes (MMP1 and MMP3) after IL6/ sIL6R treatment, showing expression levels similar to the induced with only IL6/sIL6R (Fig. 5). We also observed that mRNA expression of MMP3 was more resistant to TNF $\alpha$ withdrawal probably due to its stability. These data suggest that the observed cooperative effect requires concomitant induction by both TNF $\alpha$ and IL6/sIL6R. 


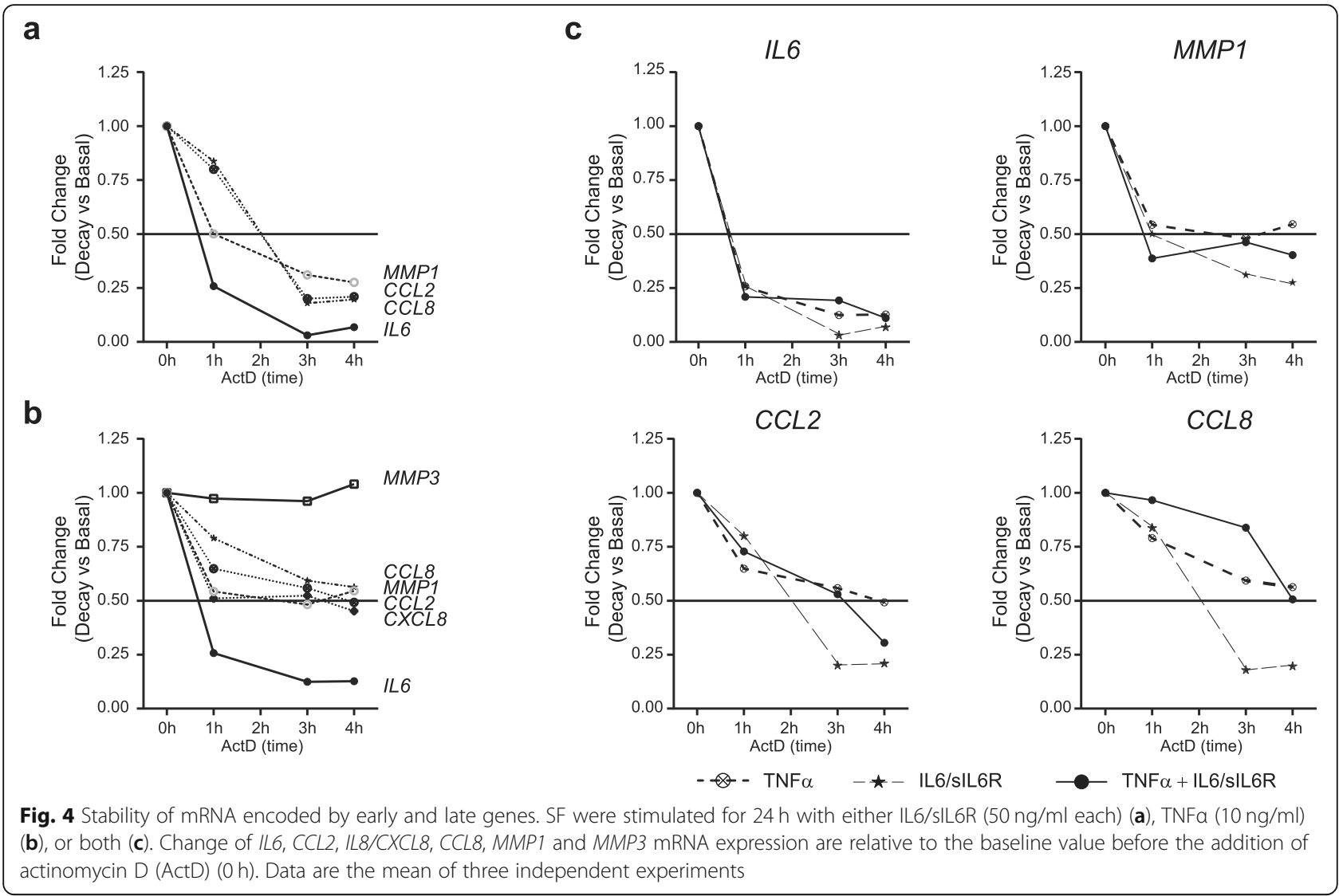

These results collectively support the view that, although regulation of the mRNA stability and priming mechanisms may determine the kinetics of TNF $\alpha$-induced gene expression, cooperative induction by TNF $\alpha$ and IL6/sIL6R is more likely mediated through coordinated de novo transcriptional mechanisms.

\section{Late crosstalk between TNFa and IL6/sIL6R is mediated by activation of the JAK-STAT pathway}

The delayed effect on the cooperative expression of genes such as CCL8, CCL2 or MMP1 (Fig. 3a) suggested that either TNF $\alpha$ or IL6/sIL6R induces secondary mechanisms dependent of new protein synthesis. This hypothesis was tested by inhibiting the protein synthesis with cycloheximide ( $\mathrm{CHX}$ ). $\mathrm{CHX}$ inhibited the expression of late genes such as CCL8 and MMP1 induced by either TNF $\alpha$ (Additional file 3: Figure S2a) or IL6/sIL6R (Additional file 3: Figure S2b), suggesting that protein-synthesis-dependent pathways are partly involved in the expression of these genes in SF, in contrast to early or intermediate genes such as IL6, IL8/CXCL8 and CCL2.

Previous investigations have demonstrated that TNF $\alpha$ stimulation of SF induces the expression of several lymphocyte-attracting chemokines through a JAK signalingmediated mechanism, dependent on autocrine release of type I Interferons (IFN) [23]. To confirm this possibility in our model, we analyzed the RSAD2 mRNA expression, a classical IFN-induced gene, after TNF $\alpha$ treatment. We observed a high induction of RSAD2 that was completely inhibited in the presence of the JAK/STAT inhibitor ruxolitinib (RUXO) (Fig. 6a). As expected, induction of IL6/sIL6R dependent genes was abrogated by RUXO treatment (Fig. 6b). Further analyses demonstrated that RUXO significantly inhibited TNF $\alpha$-induced expression of CCL2 and CCL8, implying that the secondary mediator acts through JAK/STAT. Interestingly, $M M P 1$, other late gene regulated by $\mathrm{CHX}$ was not affected by RUXO, suggesting that a JAK/STAT-independent but protein-synthesis-dependent pathways is partly involved in MMP1 expression.

These experiments further revealed that a TNF $\alpha$ induced autocrine mechanism is regulating part of the TNF $\alpha$ expression program in SF. This autocrine mechanism induced by TNF $\alpha$ shares a common JAK/STAT signaling pathway with IL6/sIL6R that may partially account for the cooperative expression of specific genes.

\section{Discussion}

The response of resident cells in the synovium is essential to RA pathogenesis and it is conditioned by inflammatory cytokines. Although, the function of the two pivotal cytokines, TNF $\alpha$ and IL6, has been extensively studied in this context, most investigations have focused 


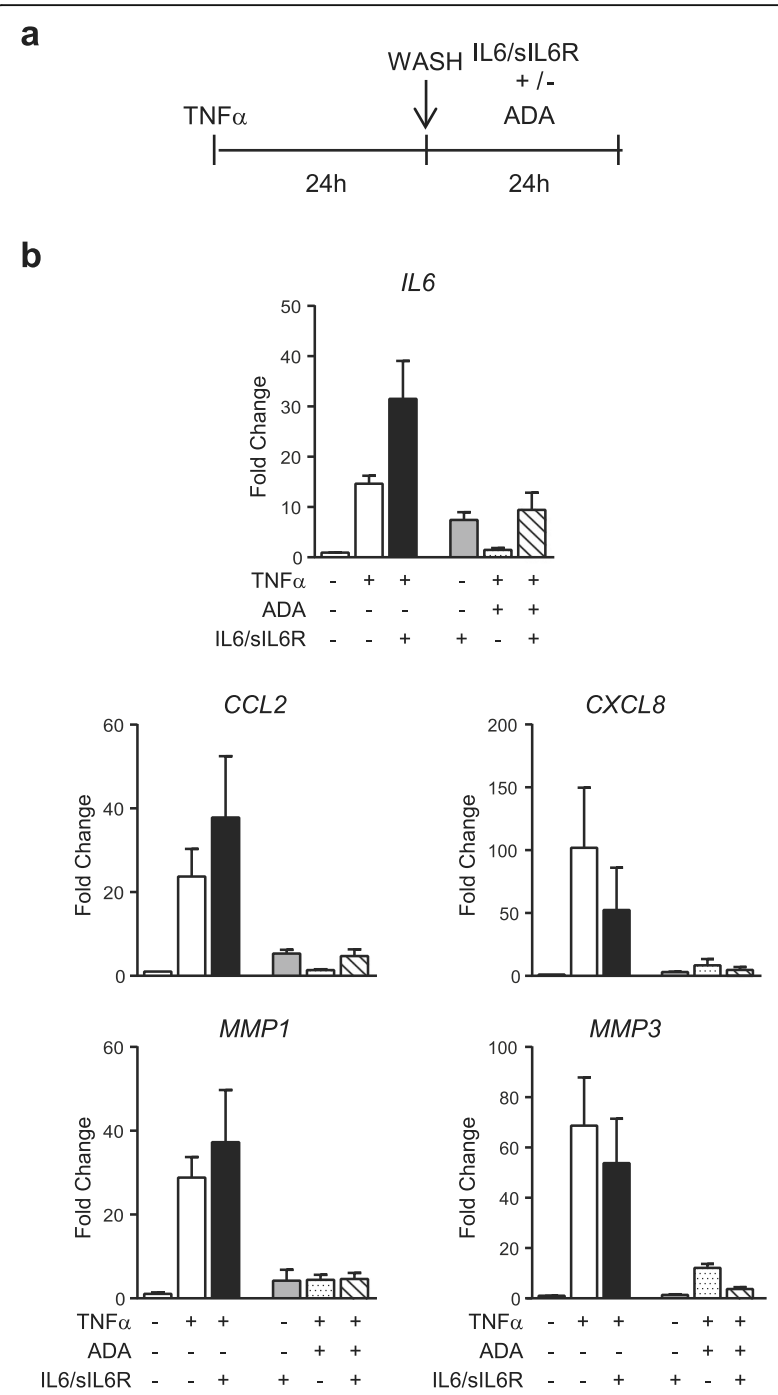

Fig. 5 Effect of adalimumab on TNFa-induced genes modulated by IL6/SIL6R. a Schematic representation of the experiment. SF were stimulated with TNFa $(10 \mathrm{ng} / \mathrm{ml})$ for $24 \mathrm{~h}$. Inflammatory input was removed by washing cells and the second stimuli IL6/sIL6R (50 ng/ $\mathrm{ml}$ each) was added in the presence of adalimumab (ADA) $(10 \mathrm{\mu g} /$ $\mathrm{ml}$ ) to block any residual TNFa. $\mathbf{b}$ Graphics show the change on the mRNA expression of representative genes. Untreated SF was used as reference. Data are mean \pm SEM of three independent experiments

on the role of TNF $\alpha$ as the main upstream inductor of IL6 expression. Our present work shows that IL6/sIL6R signaling is able to modulate the TNF $\alpha$ inflammatory response elicited in SF, promoting changes of the inflammatory gene expression pattern associated to RA pathogenesis. Furthermore, we provide insight into the molecular mechanisms that regulate the crosstalk between both cytokines.

The mode of action of IL6 is contextual, defined by other factors present within the local milieu [10]. Although IL6 is defined as an inflammatory cytokine, it does not directly induce leukocyte recruitment [15]. Rather, previous studies have shown the ability of IL6, either alone or cooperating with other factors, to modify inflammatory infiltrates [24-28]. Analysis of adjuvant-induced arthritis(AIA) in IL6 $^{+/+}$and IL6 $^{-/-}$mice demonstrated that IL6 deficiency is associated with reduced synovial infiltration and is accompanied by a defect in both CCL2 expression and the recruitment of leukocytes bearing the CCL2 receptor CCR2 [6]. Our results show that the induction of IL6/sIL6R signaling in SF mainly stimulates the expression of cytokines and chemokines that attract lymphocyte and monocyte cells, although at a lower level than TNFa. However, the cooperative activation of both factors further enhances the expression of common chemokines and cytokines, thus potentially contributing to sustain the leukocyte influx into the synovial tissue. The impact of IL6/sIL6R and TNF $\alpha$ combination in SF may be more relevant in the context of RA where the local increase of sIL6R correlates with the extent of leukocyte infiltration and joint destruction $[3,9]$. Because the expression of IL6R within the RA synovial environment is mainly restricted to leukocytes [29], infiltrating cells may be the source of the synovial sIL6R in response to inflammatory mediators such as TNF $\alpha$ [26, 30-32]. The sIL6R would then be acting as a paracrine mediator on synovial cells, further inducing leukocyte recruitment during inflammation [33]. Several studies have highlighted a role for sIL6R in regulating the expression of chemokines and adhesion molecules [8, 31, 32, 34-37], thus mediating the transition between the early neutrophilic stage of acute inflammation and the more sustained mononuclear cell influx [26]. Interestingly, mouse models of $\mathrm{IL}^{-1-}$ showed reduced neutrophil accumulation at sites of infection or inflammation that seems to be secondary to the effects of IL6 transsignaling on stromal cells [38]. Our studies demonstrate that IL6/sIL6R shapes the expression program of leukocyte recruiting factors mediated by TNF $\alpha$ in SF. In addition, these results confirm that IL6 trans-signaling directly enhanced TNFo-induced expression of monocyteand lymphocyte-regulating factors such as IL6, CCL2, and CCL8, while inhibiting the expression of the neutrophilrecruiting factor IL8/CXCL8. The functional relevance of these changes in gene expression patterns are highlighted by the increased MNC migration at the expense of PMN recruitment upon IL6/sIL6R trans-signaling. Such scenario may be relevant to arthritis, in which neutrophils may play an essential role in the initiation of RA but mononuclear leukocytes infiltration would explain chronicity $[39,40]$. In this context, regulation of the SF inflammatory response by IL6/sIL6R would be playing a major role in the transition to sustained inflammation.

The temporal order of induction and the relative duration of the various inflammatory events induced by TNF $\alpha$ and IL6/sIL6R suggests a gene activation program that ensures a rapid inflammatory response [19-21]. Kinetics and stability analyses of gene expression, as well as the differential 
a

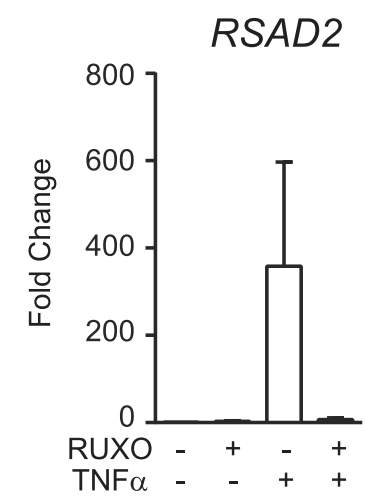

CXCL8

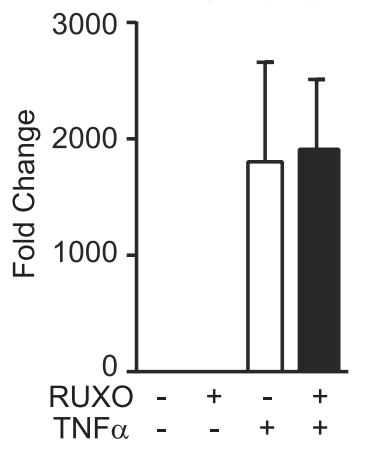

CCL8

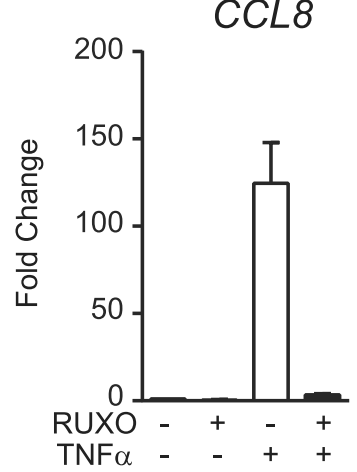

b

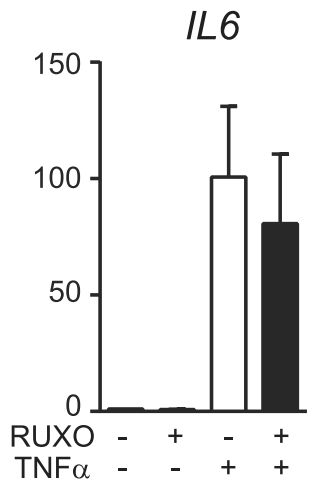

CCL2

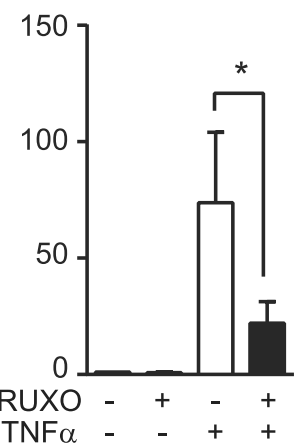

MMP1

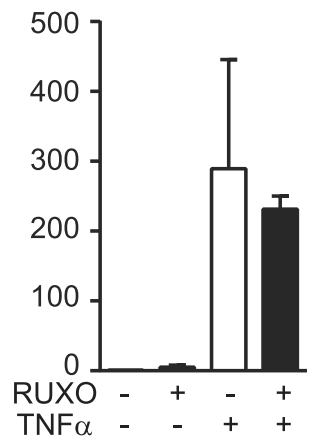

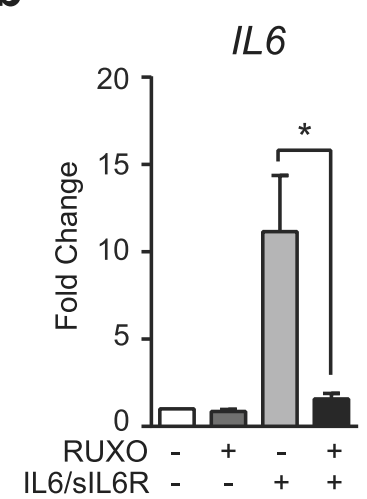
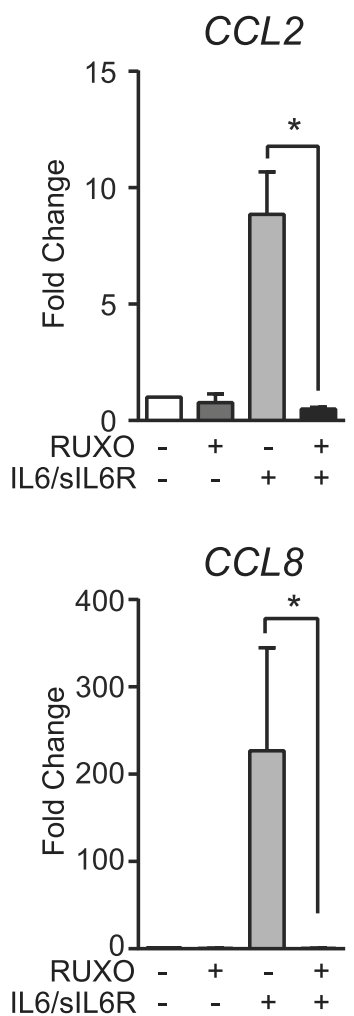

Fig. 6 Inhibition of TNFa-induced genes by ruxolitinib in SF. TNFa-induced (10 ng/ml) (a) and IL6/sll6R-induced (50 ng/ml each) (b) mRNA expression for $24 \mathrm{~h}$ in the presence and absence of ruxolitinib (RUXO) $(5 \mu \mathrm{g} / \mathrm{ml})$. Results are mean \pm SEM from three to six independent SF cultures (*Wilcoxon test)

decay for each gene induced by TNFa suggest that, similar to what is described in other cells types [19], SF display a pattern of gene expression controlled by both transcriptional and post-transcriptional mechanisms. In contrast, the fast decay observed in IL6/sIL6R-induced mRNAs suggests that de novo transcriptional mechanisms are mainly, if not exclusively, regulating the expression genes induced by IL6/ sIL6R in SF, even for the stable expression of genes such as CCL8 or MMP1. Furthermore, IL6/sIL6R signaling did not modify the stability of TNF $\alpha$-expressed mRNAs, suggesting an independent transcriptional regulation of commonly induced genes.
Evidences suggest that chronic pathological states are associated with disease-specific stable changes in gene expression, many of them consistent with epigenetic mechanisms. It has been shown that TNF $\alpha$ can display a gene-specific priming effect on RASF, mediated by epigenetic changes, that enhances subsequent inflammatory response to other factors such as IFNs [22]. However, our data do not demonstrate TNF $\alpha$ priming of gene expression induced by IL6/sIL6R. Altogether, our results suggest that the cooperative effect elicited by IL6/sIL6R in TNF $\alpha$-responses requires the sustained presence of both factors, potentially making SF more responsive to 
the pharmacological intervention with IL6/sIL6R signaling inhibitors.

IL6/sIL6R activation of SF may not only contribute to synovitis by sustaining leukocyte infiltration within the inflamed joint, but also enhancing their matrix degrading activity. Similar to previous investigations, we observed a consistent up-regulation of $M M P 1$ expression upon IL6/sIL6R stimulation of SF [41]. For most of the MMPs, TNF $\alpha$ induces activation via several transcription factors, including NF-kB and activator protein 1 (AP-1) [42]. In contrast, IL6/sIL6R effect on these genes seems to be more specific. For instance, $M M P 1$ and $M M P 3$ genes bear STAT binding sites [43] that would make them susceptible of IL6-induction by promoter-bound STAT3 or STAT1, in contrast to other MMPs gene promoters that do not have STAT motifs [44]. Although differences in the cell sources used in both studies may account for part of the discrepancies between Araki's results [41] and ours, the fact that MMP3 is not expressed at any dose tested, even under active transcriptional conditions such as those imposed by TNF $\alpha$, suggests that IL6 does not induce the recruitment of transcription factors to the MMP3 promoter, further supporting that de novo transcription has a major role in the response mediated by IL6/sIL6R signaling.

Of interest is the IL6/sIL6R inhibitory effect on TNFomediated expression of MMP10. MMP10 is linked to the control of the resolution phase of inflammation in models of pulmonary inflammation and experimental colitis, where MMP10 deficiency exacerbates the disease [18, 45, 46]. Therefore, IL6/sIL6R may also potentiate TNFo inflammatory response by restraining this anti-inflammatory loop.

\section{Conclusions}

Although our study mostly rely on mRNA expression analysis, thus limiting the interpretation of our conclusions at the pathological level, our findings places SF as a relevant target for IL6 trans-signaling response that contributes to leukocyte infiltration and joint destruction through direct effects and by modulating TNF $\alpha$ actions (Additional file 4: Figure S3), explaining the local effects of IL6-targeted DMARDs with independence of their immunoregulatory potential.

\section{Supplementary information}

Supplementary information accompanies this paper at https://doi.org/10. 1186/s12860-020-00317-7.

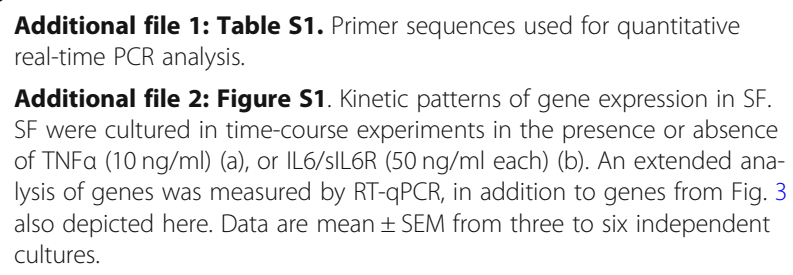

Additional file 3: Figure S2. Effect of cycloheximide on TNFa- and IL6/ slL6R-induced genes. TNFa-induced ( $10 \mathrm{ng} / \mathrm{ml}$ ) (a) and, IL6/slL6R-induced ( $50 \mathrm{ng} / \mathrm{ml}$ each) (b) mRNA expression for $24 \mathrm{~h}$ in the presence and absence of cycloheximide (CHX) $(10 \mu M)$. Mean \pm SEM from three to six independent SF cultures.

Additional file 4: Figure S3. Scheme of the cooperative role of TNFa and IL6/SIL6R in regulating the inflammatory response in SF. (a) TNFa induces a strong inflammatory response in SF during RA, mediating the infiltration of monocytic and leukocytic cells as well as neutrophils, the expression of matrix degradative metalloproteases, but also potentially activating mechanisms to control the inflammatory program. Part of these effects are mediated through activation of JAK/STAT signaling pathways. (b) In this TNFa- inflammatory context, IL6/sIL6R would be playing a major role in the transition to sustained inflammation, enhancing leukocyte infiltration and joint destruction.

\section{Abbreviations}

ActD: Actinomycin D; ADA: Adalimumab; CHX: Cycloheximide; DMAR Ds: Disease-modifying antirheumatic drugs; DMEM: Dulbecco's modified Eagle's medium; ELISA: Enzyme-linked immunosorbent assay; FBS: Fetal bovine serum; IFN: Interferon; IL6: Interleukin-6; MMP: Matrix metalloprotease; MNC: Mononuclear cells; PMN: Polymorphonuclear; RA: Rheumatoid arthritis; RASF: Rheumatoid Arthritis Synovial Fibroblasts; RT-qPCR: Quantitative RTPCR; RUXO: Ruxolitinib; SF: Synovial fibroblasts; IIL6R: Soluble IL6 receptor

\section{Acknowledgements}

We are grateful to the Servicio de Traumatología y Cirugía Ortopédica (Hospital 12 de Octubre, Madrid, Spain) for synovial biopsies and to Vanessa Miranda for technical assistance.

\section{Authors' contributions}

$A V, M J D, G C$ and JLP conceived and designed the experiments. AV, MJD, CM, $A U, M R, J F F$ and YR performed the research, collected and analyzed data. JDC, FJB and JLP provided samples. AV, MJD, CM, JDC, FJB, GC and JLP interpreted data. AV, MJD, GC and JLP wrote the paper. All authors read and approved the final manuscript.

\section{Funding}

This work was supported by the Fondo de Investigación Sanitaria, Instituto de Salud Carlos III (FIS 16/00032, RETICS RD16/0012 RIER) cofinanced by European Regional Development Fund (FEDER).

\section{Availability of data and materials}

The datasets analyzed in the current study are available from the corresponding author on reasonable request.

\section{Ethics approval and consent to participate}

The study was approved by the Ethics Committee of Hospital 12 de Octubre, Madrid, Spain ( $\mathrm{N}^{\circ}$ CEl:17/085). All patients signed a written informed consent.

\section{Consent for publication}

Not applicable.

\section{Competing interests}

AV is currently working as editor at Springer Healthcare Iberica SL, Madrid, Spain. All other authors declare no competing financial interests.

\section{Author details}

'Grupo de Enfermedades Inflamatorias y Autoinmunes, Instituto de Investigación Hospital 12 de Octubre (i+12), Madrid, Spain. ${ }^{2}$ Present Address: Springer Healthcare Iberica SL, Madrid, Spain. ${ }^{3}$ Unitat d'Artritis, Servei de Reumatologia, Hospital Clínic de Barcelona and Institut d'Investigacions Biomèdiques August Pí i Sunyer, Barcelona, Spain. ${ }^{4}$ Laboratorio de Investigación Osteoarticular y del Envejecimiento, Instituto de Investigación Biomédica de A Coruña, INIBIC, A Coruña, Spain. ${ }^{5}$ Servicio de Anatomía Patológica, Instituto de Investigación Hospital 12 de Octubre (i+12), Madrid, Spain. ${ }^{6}$ Servicio de Reumatología, Hospital 12 de Octubre, Universidad Complutense de Madrid, 28041 Madrid, Spain. 
Received: 27 May 2020 Accepted: 14 October 2020 Published online: 30 October 2020

\section{References}

1. Lipsky PE. Interleukin-6 and rheumatic diseases. Arthritis Res Ther. 2006;8 Suppl 2:S4.

2. Houssiau FA, Devogelaer JP, Van Damme J, de Deuxchaisnes CN, Van Snick J. Interleukin-6 in synovial fluid and serum of patients with rheumatoid arthritis and other inflammatory arthritides. Arthritis Rheum. 1988;31(6):784-8.

3. Robak T, Gladalska A, Stepien H, Robak E. Serum levels of interleukin-6 type cytokines and soluble interleukin-6 receptor in patients with rheumatoid arthritis. Mediat Inflamm. 1998;7(5):347-53.

4. Kishimoto T, Taga T, Yamasaki K, Matsuda T, Tang B, Muraguchi A, Horii Y, Suematsu S, Hirata Y, Yawata H, et al. Normal and abnormal regulation of human B cell differentiation by a new cytokine, BSF2/IL-6. Adv Exp Med Biol. 1989:254:135-43.

5. Firestein GS, Alvaro-Gracia JM, Maki R. Quantitative analysis of cytokine gene expression in rheumatoid arthritis. J Immunol. 1990;144(9):3347-53.

6. Nowell MA, Richards PJ, Horiuchi S, Yamamoto N, Rose-John S, Topley N, Williams AS, Jones SA. Soluble IL-6 receptor governs IL-6 activity in experimental arthritis: blockade of arthritis severity by soluble glycoprotein 130. J Immunol. 2003;171(6):3202-9.

7. Desgeorges A, Gabay C, Silacci P, Novick D, Roux-Lombard P, Grau G, Dayer JM, Vischer T, Guerne PA. Concentrations and origins of soluble interleukin 6 receptor-alpha in serum and synovial fluid. J Rheumatol. 1997;24(8):1510-6.

8. Hunter CA, Jones SA. IL-6 as a keystone cytokine in health and disease. Nat Immunol. 2015;16(5):448-57.

9. Kotake S, Sato K, Kim KJ, Takahashi N, Udagawa N, Nakamura I, Yamaguchi A, Kishimoto T, Suda T, Kashiwazaki S. Interleukin-6 and soluble interleukin-6 receptors in the synovial fluids from rheumatoid arthritis patients are responsible for osteoclast-like cell formation. J Bone Miner Res. 1996;11(1):88-95.

10. McGettrick HM, Butler LM, Buckley CD, Rainger GE, Nash GB. Tissue stroma as a regulator of leukocyte recruitment in inflammation. J Leukoc Biol. 2012 91(3):385-400

11. Kaneshiro K, Sakai Y, Suzuki K, Uchida K, Tateishi K, Terashima Y, Kawasaki Y, Shibanuma N, Yoshida K, Hashiramoto A. Interleukin-6 and tumour necrosis factor-a cooperatively promote cellcycle regulators and proliferate rheumatoid arthritis fibroblast-like synovial cells. Scand J Rheumatol. 2019;0:1-9.

12. Jones DS, Jenney AP, Swantek JL, Burke JM, Lauffenburger DA, Sorger PK Profiling drugs for rheumatoid arthritis that inhibit synovial fibroblast activation. Nat Chem Biol. 2017:13(1):38-45.

13. Kalliolias GD, Ivashkiv LB. TNF biology, pathogenic mechanisms and emerging therapeutic strategies. Nat Rev Rheumatol. 2016;12(1):49-62.

14. Filer A, Parsonage G, Smith E, Osborne C, Thomas AM, Curnow SJ, Rainger GE, Raza K, Nash GB, Lord J, et al. Differential survival of leukocyte subsets mediated by synovial, bone marrow, and skin fibroblasts: site-specific versus activation-dependent survival of T cells and neutrophils. Arthritis Rheum. 2006:54(7):2096-108

15. McGettrick HM, Smith E, Filer A, Kissane S, Salmon M, Buckley CD, Rainger GE, Nash GB. Fibroblasts from different sites may promote or inhibit recruitment of flowing lymphocytes by endothelial cells. Eur J Immunol. 2009;39(1):113-25.

16. del Rey MJ, Izquierdo E, Caja S, Usategui A, Santiago B, Galindo M, Pablos JL. Human inflammatory synovial fibroblasts induce enhanced myeloid cell recruitment and angiogenesis through a hypoxia-inducible transcription factor 1alpha/vascular endothelial growth factor-mediated pathway in immunodeficient mice. Arthritis Rheum. 2009;60(10):2926-34.

17. Smolen JS, Aletaha D, McInnes IB. Rheumatoid arthritis. Lancet. 2016; 388(10055):2023-38.

18. McMahan RS, Birkland TP, Smigiel KS, Vandivort TC, Rohani MG, Manicone AM, McGuire JK, Gharib SA, Parks WC. Stromelysin-2 (MMP10) moderates inflammation by controlling macrophage activation. J Immunol. 2016;197(3): 899-909.

19. Hao S, Baltimore D. The stability of mRNA influences the temporal order of the induction of genes encoding inflammatory molecules. Nat Immunol. 2009;10(3):281-8

20. Paulsen MT, Veloso A, Prasad J, Bedi K, Ljungman EA, Tsan YC, Chang CW Tarrier B, Washburn JG, Lyons R, et al. Coordinated regulation of synthesis and stability of RNA during the acute TNF-induced proinflammatory response. Proc Natl Acad Sci U S A. 2013;110(6):2240-5.
21. Loupasakis K, Kuo D, Sokhi UK, Sohn C, Syracuse B, Giannopoulou EG, Park $\mathrm{SH}$, Kang H, Ratsch $\mathrm{G}$, Ivashkiv LB, et al. Tumor necrosis factor dynamically regulates the mRNA stabilome in rheumatoid arthritis fibroblast-like synoviocytes. PLoS One. 2017;12(7):e0179762.

22. Sohn C, Lee A, Qiao Y, Loupasakis K, Ivashkiv LB, Kalliolias GD. Prolonged tumor necrosis factor alpha primes fibroblast-like synoviocytes in a gene-specific manner by altering chromatin. Arthritis Rheumatol. 2015;67(1):86-95.

23. Rosengren S, Corr M, Firestein GS, Boyle DL. The JAK inhibitor CP-690,550 (tofacitinib) inhibits TNF-induced chemokine expression in fibroblast-like synoviocytes: autocrine role of type I interferon. Ann Rheum Dis. 2012:71(3):440-7.

24. Tilg H, Dinarello CA, Mier JW. IL-6 and APPs: anti-inflammatory and immunosuppressive mediators. Immunol Today. 1997;18(9):428-32.

25. Ulich TR, Yin S, Guo K, Yi ES, Remick D, del Castillo J. Intratracheal injection of endotoxin and cytokines. II. Interleukin- 6 and transforming growth factor beta inhibit acute inflammation. Am J Pathol. 1991;138(5):1097-101.

26. Hurst SM, Wilkinson TS, McLoughlin RM, Jones S, Horiuchi S, Yamamoto N, Rose-John S, Fuller GM, Topley N, Jones SA. II-6 and its soluble receptor orchestrate a temporal switch in the pattern of leukocyte recruitment seen during acute inflammation. Immunity. 2001;14(6):705-14.

27. Kaplanski G, Marin V, Montero-Julian F, Mantovani A, Farnarier C. IL-6: a regulator of the transition from neutrophil to monocyte recruitment during inflammation. Trends Immunol. 2003;24(1):25-9.

28. Rose-John S, Waetzig GH, Scheller J, Grotzinger J, Seegert D. The IL-6/sIL-6R complex as a novel target for therapeutic approaches. Expert Opin Ther Targets. 2007;11(5):613-24.

29. Jones SA, Horiuchi S, Topley N, Yamamoto N, Fuller GM. The soluble interleukin 6 receptor: mechanisms of production and implications in disease. FASEB J. 2001;15(1):43-58.

30. Jones SA, Novick D, Horiuchi S, Yamamoto N, Szalai AJ, Fuller GM. C-reactive protein: a physiological activator of interleukin 6 receptor shedding. J Exp Med. 1999;189(3):599-604.

31. Marin V, Montero-Julian FA, Gres S, Boulay V, Bongrand P, Farnarier C, Kaplanski G. The IL-6-soluble IL-6Ralpha autocrine loop of endothelial activation as an intermediate between acute and chronic inflammation: an experimental model involving thrombin. J Immunol. 2001;167(6):3435-42.

32. Modur V, Li Y, Zimmerman GA, Prescott SM, McIntyre TM. Retrograde inflammatory signaling from neutrophils to endothelial cells by soluble interleukin-6 receptor alpha. J Clin Invest. 1997;100(11):2752-6.

33. Jones SA, Rose-John S. The role of soluble receptors in cytokine biology: the agonistic properties of the $s \mid L-6 R / I L-6$ complex. Biochim Biophys Acta. 2002; 1592(3):251-63

34. Romano $M$, Sironi $M$, Toniatti $C$, Polentarutti $N$, Fruscella $P$, Ghezzi $P$, Faggioni R, Luini W, van Hinsbergh V, Sozzani S, et al. Role of IL-6 and its soluble receptor in induction of chemokines and leukocyte recruitment. Immunity. 1997;6(3):315-25.

35. Klouche M, Rose-John S, Schmiedt W, Bhakdi S. Enzymatically degraded, nonoxidized LDL induces human vascular smooth muscle cell activation, foam cell transformation, and proliferation. Circulation. 2000;101(15):1799-805.

36. Matsumiya T, Imaizumi T, Fujimoto K, Cui X, Shibata T, Tamo W, Kumagai M, Tanji K, Yoshida H, Kimura H, et al. Soluble interleukin-6 receptor alpha inhibits the cytokine-induced fractalkine/CX3CL1 expression in human vascular endothelial cells in culture. Exp Cell Res. 2001;269(1):35-41.

37. Oh JW, Van Wagoner NJ, Rose-John S, Benveniste EN. Role of IL-6 and the soluble IL-6 receptor in inhibition of VCAM-1 gene expression. J Immunol. 1998;161(9):4992-9.

38. Jones SA. Directing transition from innate to acquired immunity: defining a role for IL-6. J Immunol. 2005;175(6):3463-8.

39. Wipke BT, Allen PM. Essential role of neutrophils in the initiation and progression of a murine model of rheumatoid arthritis. J Immunol. 2001; 167(3):1601-8

40. Pope RM. Apoptosis as a therapeutic tool in rheumatoid arthritis. Nat Rev Immunol. 2002;2(7):527-35.

41. Araki Y, Tsuzuki Wada T, Aizaki Y, Sato K, Yokota K, Fujimoto K, Kim YT, Oda H, Kurokawa R, Mimura T. Histone methylation and STAT-3 differentially regulate Interleukin-6-induced matrix metalloproteinase gene activation in rheumatoid arthritis synovial fibroblasts. Arthritis Rheumatol. 2016;68(5):1111-23.

42. Martel-Pelletier J, Welsch DJ, Pelletier JP. Metalloproteases and inhibitors in arthritic diseases. Best Pract Res Clin Rheumatol. 2001;15(5):805-29.

43. Cutler SJ, Doecke JD, Ghazawi I, Yang J, Griffiths LR, Spring KJ, Ralph SJ, Mellick AS. Novel STAT binding elements mediate IL-6 regulation of MMP-1 and MMP-3. Sci Rep. 2017;7(1):8526. 
44. Zhao X, Nozell S, Ma Z, Benveniste EN. The interferon-stimulated gene factor 3 complex mediates the inhibitory effect of interferon-beta on matrix metalloproteinase-9 expression. FEBS J. 2007;274(24):6456-68.

45. Kassim SY, Gharib SA, Mecham BH, Birkland TP, Parks WC, McGuire JK. Individual matrix metalloproteinases control distinct transcriptional responses in airway epithelial cells infected with Pseudomonas aeruginosa. Infect Immun. 2007;75(12): 5640-50.

46. Koller FL, Dozier EA, Nam KT, Swee M, Birkland TP, Parks WC, Fingleton B. Lack of MMP10 exacerbates experimental colitis and promotes development of inflammation-associated colonic dysplasia. Lab Investig. 2012;92(12):1749-59.

\section{Publisher's Note}

Springer Nature remains neutral with regard to jurisdictional claims in published maps and institutional affiliations.

Ready to submit your research? Choose BMC and benefit from:

- fast, convenient online submission

- thorough peer review by experienced researchers in your field

- rapid publication on acceptance

- support for research data, including large and complex data types

- gold Open Access which fosters wider collaboration and increased citations

- maximum visibility for your research: over $100 \mathrm{M}$ website views per year

At $\mathrm{BMC}$, research is always in progress.

Learn more biomedcentral.com/submissions 